\title{
Spatial relationships between tree species and gap characteristics in broad-leaved deciduous woodland
}

\author{
Koukoulas, Sotirios $^{1 *}$ \& Blackburn, George Alan ${ }^{2}$ \\ ${ }^{1}$ Geography Department, University of the Aegean, University Hill, Mytilene 81100, Greece; \\ ${ }^{2}$ Department of Geography, Lancaster University, Lancaster LA1 4YB, UK; E-mail alan.blackburn@lancaster.ac.uk; \\ *Corresponding author; Fax +30 2251036409; E-mail skouk@geo.aegean.gr; www.aegean.gr/geography
}

\begin{abstract}
Questions: 1. What are the spatial patterns of all trees, individual tree species, trees within particular height classes, all gaps and gaps with specific properties across the study site in broad-leaved deciduous forest at a range of scales? 2. Are patterns of the above features spatially associated? 3. Are these patterns indicative of gap creation mechanisms and phases of regeneration?

Location: Frame Wood, New Forest, UK.

Methods: Ripley's $K$-function analysis was applied to spatial information derived from airborne remotely sensed imagery to characterize the patterns of trees and gaps and to test for spatial interactions between these patterns. The patterns of trees and gaps with specific physical and spatial properties were analysed.

Results: The pattern of all tree species combined was random for most scales; Quercus robur followed the same random pattern, while Fagus sylvatica and Betula pendula were clustered over most spatial scales. Large gaps $\left(>250 \mathrm{~m}^{2}\right)$ and larger trees $(>17.5 \mathrm{~m})$ were randomly distributed, while smaller gaps and smaller trees were clustered. Significant spatial relationships were demonstrated between the patterns of different tree species and between trees within different size classes, as well as between the patterns of trees and gaps with specific properties.

Conclusions: Small gap patterns and field evidence indicated that progressive gap enlargement is the most likely creation mechanism for large gaps $\left(>250 \mathrm{~m}^{2}\right)$. Clustered patterns of younger individuals were indicative of patches of past regeneration. As a complement to field-based data, data derived from remotely sensed imagery provides spatially comprehensive information with which to further investigate woodland stand/community processes and gap dynamics.
\end{abstract}

Keywords: Frame Wood; Gap-tree spatial relationship; Forest spatial structure; New Forest; Remote sensing; Ripley's $K$ function; Spatial point pattern.

\footnotetext{
Abbreviations: $\mathrm{ATM}=$ Airborne thematic mapper; $\mathrm{CHM}=$ Canopy height model; CSR = Complete spatial randomness; GHD = Gap height diversity; GSCI = Gap shape complexity index; LiDAR = Light detection and ranging.
}

\section{Introduction}

Changes to the spatial structure of a woodland canopy, caused by natural or anthropogenic disturbances, have consequences for a vast range of biotic and abiotic phenomena and processes. To understand the effects of these canopy changes, the spatial structure needs to be quantified and monitored. This demands that we define clearly the meaning of canopy spatial structure and identify suitable measurement techniques. Campbell \& Norman (1989) defined plant canopy structure as the spatial arrangement of the above-ground organs of plants in a community and they indicated that quantifying structure involves identifying the position, size and spacing of each element in the canopy. Ross (1981) suggested that comprehensive plant canopy descriptions should include measurements at four levels of organisation: individual organs, the whole plant, the stand and the plant community. However, collecting information for all these levels is clearly impossible taking into account that "canopies vary on spatial scales from millimetres to kilometres, and on time scales ranging from milliseconds to decades" (Campbell \& Norman 1989). Hence, it is usually necessary to work within one level of organisation.

The present study focuses on the spatial structure within woodland stands. Previous work at this level has followed two approaches. Firstly, many studies have focused on the importance of gap openings and have demonstrated the associations between gap characteristics and ecosystem functioning and the importance of gaps in determining species composition and controlling regeneration processes (e.g. Runkle 1982; Platt \& Strong 1989). Secondly, canopy structure has been studied as the vertical and horizontal spatial arrangement of plant species, plant sizes, age or diameter distributions (e.g. Duncan \& Stewart 1991; Dale 1999; Roberts et al. 2000). The significance of tree distributions and spatial interactions has been highlighted by many authors as the patterns formed by trees affect regeneration, growth, mortality, propa- 
gation of disturbance and often drive management decisions (e.g. Szwagrzyk \& Czerwczak 1993; Haase 1995; Stoyan \& Penttinen 2000). The spatial patterns of trees in woodlands reflect their history, management, and ecology. A series of events have led to the mosaic that is observed at a specific time. The study of this mosaic allows the analyst to understand better ecological processes especially if changes in patterns are monitored over a period of time. Methodologies used include one-dimensional descriptors (stem density, basal area, canopy cover, number of canopy layers, statistics of tree diameters or heights and diversity), two-dimensional descriptors (point pattern analysis and geo-statistical tools) and most recently structure complexity indices, which take into account the three dimensions in the tree canopy structure (Zenner \& Hibbs 2000).

The present research combines the two approaches and is concerned with the spatial structure and interrelationships of both gaps and trees. At the scale of whole stands, information on gap characteristics and tree canopy properties is time consuming and expensive to obtain using traditional field techniques. However, high spatial resolution multi-spectral remotely sensed imagery can be used to quantify, using semiautomated methods, spatial properties and composition of tree canopy and gap vegetation efficiently for large areas of woodland (Blackburn \& Milton 1996, 1997; Jackson et al. 2000). Furthermore, airborne LiDAR (Light Detection and Ranging) systems (see Wehr \& Lohr 1999) have recently been developed which can generate accurate, high resolution canopy height models (CHM) of forest canopies that have the potential to provide information on individual crowns and openings. The information derived from remote sensing has a high spatial resolution, broad and continuous spatial coverage and it is collected near-simultaneously using a consistent and objective methodology for the entire study area. Such data provides a strong basis on which to begin to analyse the spatial structure of a woodland.

The objectives of this study were to: (1) analyse the spatial patterns of all trees, individual tree species, trees within particular height classes, all gaps and gaps with specific properties across the study site at a range of scales; (2) investigate whether the patterns of the above features are spatially associated; and (3) examine whether these patterns are indicative of gap creation mechanisms and whether they reveal patches of past regeneration.

\section{Study site}

The research was located in the New Forest, southern England, an area recognized as being of international importance to nature conservation. There are 4049 ha of unenclosed primary woodland where the dominant tree species are Quercus (robur and petraea) and Fagus sylvatica. Betula (pendula and pubescens) can be found mainly in canopy gaps and in association with Quercus (robur and petraea) on acid soils (Morgan 1987). Ilex aquifolium is the dominant understorey shrub. There are two or more generations of trees, with the oldest, referred to as generation 'A' mainly consisting of Quercus, Fagus and Ilex established in the late 16th / early 17th century. There are two sub-generations: A1 containing pollarded trees with a large $(>4 \mathrm{~m})$ girth and A2 that includes younger non-pollarded trees with girth between $2.5-4.0 \mathrm{~m}$. Generation ' $\mathrm{B}$ ' is much younger and appears mainly where A1 generation trees have died or been felled. Most B generation Quercus (robur and petraea) and Fagus are within a range of $1-2 \mathrm{~m}$ girth but there are many exceptions and some overlap with the A generation. Generation ' $\mathrm{C}$ ' (girth $<1 \mathrm{~m}$ ) represents later (late 18th / early 19th century) colonization of gaps, clearings, glades and woodland margins, mainly by Betula (pendula and pubescens) and Quercus (robur and petraea). The $\mathrm{C}$ generation benefited from the removal of forest deer in the 1850s, which produced a burst of natural regeneration. Detailed information concerning tree generations in the New Forest can be found in Flower (1977), Tubbs (1986) and Goriup (1999).

The specific study site, Frame Wood presents a wide range in all of the gap and canopy variables of interest, being described by Flower (1977) as a primary woodland dominated by Quercus robur with an age profile starting with the A2 generation. He also noted that Fagus was absent until the B generation but accounted for a quarter of the trees in the area. Betula pendula is found in Frame Wood and gap vegetation consists predominantly of Pteridium aquilinum and grasses that have been maintained by high grazing pressure and have a low, tight sward.

\section{Methods}

Input data for the spatial analyses consisted of the location and other properties of all individual trees and gaps across the study site which were derived from airborne LiDAR and ATM (Airborne Thematic Mapper) imagery. A Canopy Height Model (CHM) was derived from the LiDAR data and a set of procedures using image contouring and the manipulation of the resulting polygons were implemented to extract tree 
tops from the aerial photographs and the CHM. The technique that was developed, isolated first the upper tree crowns and then identified the tree tops. The species of each tree was identified using a supervised multispectral classification of the ATM images. As with any trained technique/algorithm, there were errors that led to unidentified trees (point features). These were random errors and the unidentified point features were uniformly distributed among classes, so their exclusion had minimal effect on the outputs of the spatial point pattern analysis. Small trees present beneath the main canopy were not recorded as the LiDAR instrument used only provided information on the characteristics of the upper surface of the tree canopy. The extent of each gap was defined at a certain threshold height in the CHM, dependent on the height of the surrounding tree crowns. For this particular forest type the threshold value was $4 \mathrm{~m}$ and this isoline within the CHM determined the gap boundaries.

For each gap the following characteristics were determined: height diversity within the gap; dominant vegetation type from classified ATM imagery; the area; and, shape complexity. Gap shape complexity index (GSCI), was calculated using Patton's diversity or edge index (Patton 1975):

$$
\text { GSCI }=\frac{\text { Gap perimeter }}{2 * \sqrt{\text { Gap area } * \pi}}
$$

Gaps were subsequently classified on the basis of their shape complexity index using Jenk's algorithm (Low Shape Complexity: 1.13 - 1.73, High shape complexity: > 1.73). The circle with a shape complexity index of 1 (a square has 1.13 or $13 \%$ complexity) was used as a reference. The most complex gap (GSCI = $2.64 ; 164 \%$ complexity) in the plot area was 12.6 times more complex than a square. The use of LiDAR imagery made possible the study of vegetation surface topography within gaps. Height diversity within gaps (GHD) was quantified with the Shannon formula (Shannon \& Weaver 1949):

$$
G H D=-\sum_{i=1}^{N} p_{i} \ln p_{i}
$$

where $p_{i}$ is the proportion of gap grid cells in the $i$ th height class (classes: 0, 0-1, 1-2, 2-3, 3-4, in m). Gaps were subsequently divided into two classes using Jenk's algorithm: Low Height Diversity: 0.33 - 1.12, and High Height Diversity: $1.12-1.58$. The procedures used to extract the tree and gap data from remotely-sensed imagery and assessments of the accuracy of these procedures are detailed in Koukoulas (2001) and Koukoulas \& Blackburn (2001, 2004, 2005). For this study, a rectangular plot area $400 \mathrm{~m} \times 200 \mathrm{~m}$ was selected with the assumptions of stationarity and isotropy in effect. The algorithm used for the point pattern analysis which dealt with boundary effects (Moeur 1993, 1995), required a rectangular area and this plot was the largest rectangle that fitted within Frame Wood. Fig. 1 shows the plot area and the tree species and gap distributions.

The $K$-function $K(d)$ (Ripley 1976, 1977) was used to test for deviations from CSR (Complete Spatial Randomness) for single point patterns and deviations from spatial independence for pairs of point patterns. Wiegand \& Maloney (2004) provide a detailed review of point pattern analysis in ecology. A suitable estimate of $K(d)$, taking into account corrections for edge effects, is given by:
Fig. 1. Tree and gap spatial patterns, Frame Wood, New Forest, England.

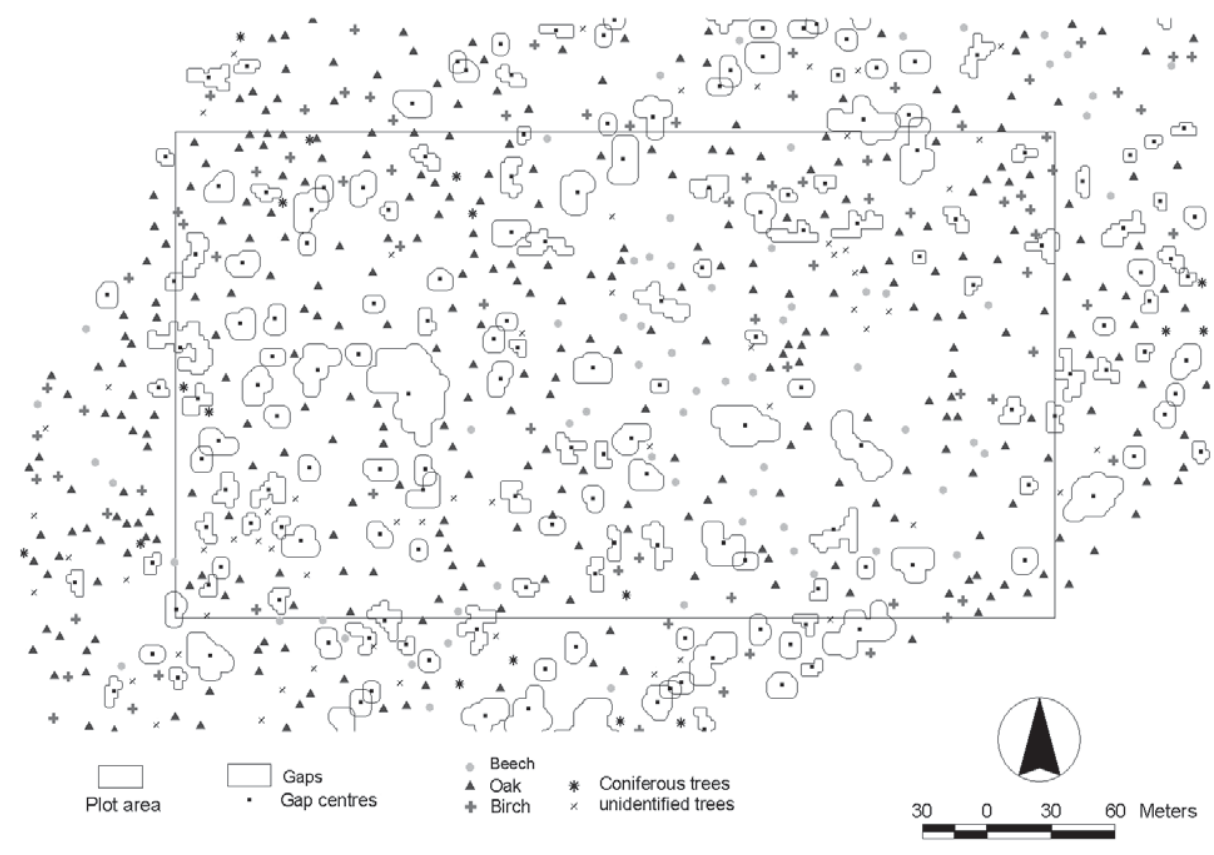


$\widehat{K}(d)=A \sum_{i=1}^{n} \sum_{j=1}^{n} \frac{w_{i j}(d)}{n^{2}}$, for $i \neq j$

for all pairs of events with $d_{i j} \leq d$, where $A$ is the area of the plot, $d_{i j}$ is the distance between event $i$ and event $j$ (trees or gaps in this case), and $d$ is the radius of the search circle centred on event $i, n$ is the number of events in the plot, and $w_{i j}(d)$ is reciprocal to the proportion of the perimeter of a circle centred on event $i$ and passing through event $j$, lying within the plot. The value of $w_{i j}(d)$ is equal to 1 for a circle wholly contained to the plot area and greater than 1 when edge correction is required. Besag (1977) suggested the following modification:

$\hat{L}(d)=\sqrt{\frac{\hat{K}(d)}{n}}-d$

Here, $L(d)$ stabilizes $K(d)$ variance, linearizes its curve and has an expected value of approximately zero under the Poisson assumption (Chen \& Bradshaw 1999). An overall test of departures from a random distribution is evaluated by determining a $95 \%$ Monte Carlo envelope. Hypothesis tests involve comparisons of the observed distribution and the estimated $L(d)$ with the values generated from multiple realisations generated from a Poisson model.

A bivariate version of the $K$-function was used to test for interactions between pairs of point patterns. A modified bivariate formula for estimating $L_{12}(d)$ is used replacing $K(d)$ with estimated $K_{12}(d)$ function. RIPK software (Moeur 1995) was used to calculate both $L(d)$ and $L_{12}(d)$ estimates. Two Avenue ${ }^{\mathrm{TM}}$ scripts were written to connect RIPK with Arcview GIS software and automate the procedure. Confidence envelopes were created using 100 Monte Carlo iterations, considered adequate for a conventional 5\% level (Diggle 1983, p. 8 ). The $K$-function analysis was applied in three stages:

1. Pattern analysis of tree species and gaps. The spatial pattern of all trees, individual tree species and gap centres were tested for deviation from CSR and pairs of all combinations of these patterns were tested for independence.

2. Pattern analysis of tree height classes. Trees were divided into two height categories using Jenk's 'natural breaks' classification algorithm. While other researchers (e.g. Chen \& Bradshaw 1999) have used three categories, minimal recent regeneration at the present study site, causing an absence of small trees, meant only two height categories could be distinguished using the classification algorithm, those $<17.5 \mathrm{~m}$ and those $>17.5 \mathrm{~m}$. The spatial patterns of each of these height classes were tested for deviation from CSR and the independence of the two classes was tested.
3. Pattern analysis of gap classes and tree species. Gaps were divided into two classes using Jenk's algorithm for each of the properties: area, height diversity and shape complexity. There were also two classes of dominant vegetation type within gaps: Pteridium and grass. The patterns of each of these classes of gap properties were each tested for deviations from CSR. Tests were then performed for independence between the patterns of each of these classes of gap properties and the patterns of each tree species.

In order to help interpret the results from the above analysis some field measurements were made. Crown width was measured for 63 randomly chosen Quercus robur trees. Gap age was estimated using log decay scale developed by Sernander (1936), revised by Hytteborn \& Packham (1987) and extended by Liu \& Hytteborn (1991). While this approach was developed in boreal forest environments, it did provide a means of estimating gap age with relative accuracy in the absence of an equivalent technique developed specifically for temperate deciduous forest. Using this method 16 logs were sampled to provide estimates of gap ages. Attempts to derive allometric relationships between tree age and geometry failed, therefore we followed a simple approach to give us a broad indication of tree age class. Using evidence from a neighbouring Quercus robur plantation (planted in 1856 with current mean height of $24 \mathrm{~m}$ ) we were able to classify the trees in our study area under the $17.5 \mathrm{~m}$ threshold as belonging to generation $\mathrm{C}$.

\section{Results and Discussion}

\section{Pattern analysis of tree species and gaps}

Fig. 2 shows the results of using Ripley's $K$-function to test for deviations from CSR, where $L(d)$ values within the $95 \%$ envelope indicate random patterns, those above the envelope indicate clustered patterns and below the envelope regular patterns. Hence, Fig. 2a shows that the point pattern for all trees shows a regular distribution up to a scale of $14 \mathrm{~m}$. This is an artefact of the size of the objects with which each of the points in the distribution is associated. Here, the points are the centres of crowns which, for the study area, had widths in the range 2 to $25 \mathrm{~m}$ (Fig. 3). Crown width dimensions control the distances between adjacent crown centres and induce a regularity of distribution. Fig. 2a also demonstrates that for spatial scales above $14 \mathrm{~m}$ the pattern of all trees is random and this was expected for semi-natural woodland. Quercus robur trees account for the majority of trees in the study area and their random pattern over the majority of scales (Fig. 2b) appears to determine the pattern of all tree species 
a)

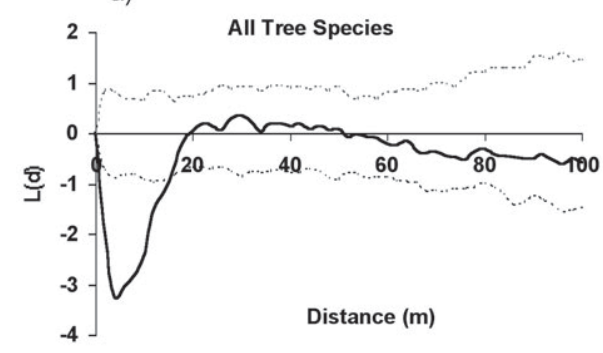

c)
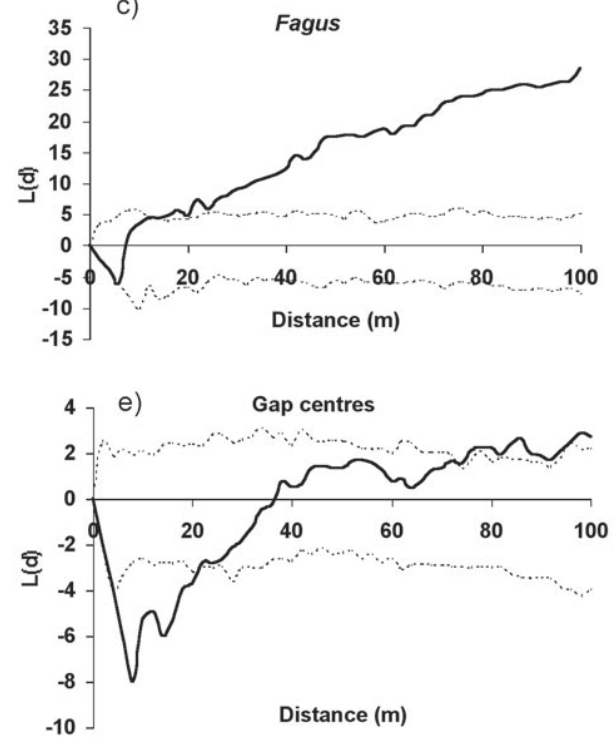

b)

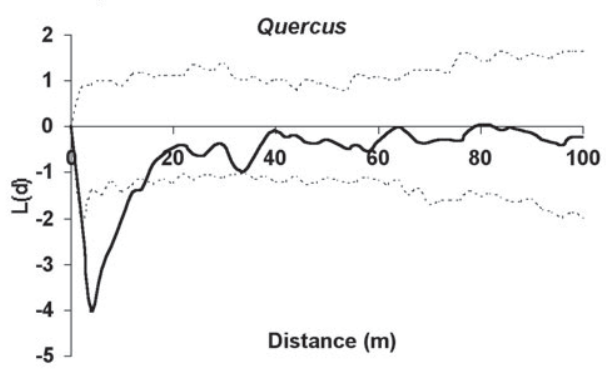

d)

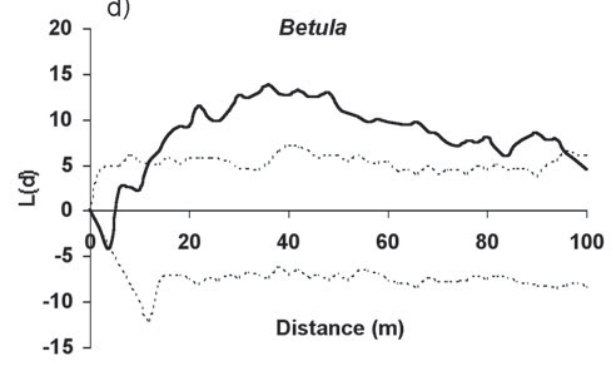

combined (Fig. 2a). Fagus and Betula pendula trees show a different spatial pattern to $Q$. robur as they are clustered over most spatial scales (Fig. 2c, d). Research in the study area by Flower (1977) suggested that Fagus was absent in the A generation and established later, being part of B generation. The latter explains the clustered pattern of Fagus which are mainly contained within one large cluster (see Fig. 1 - Fagus trees are grouped on the east side of the area) and represent the remaining trees of a generation (there is no recent evidence of Fagus regeneration in the woodland). The clustering of $B$. pendula trees concurs with the observation that this wind-dispersed, light demanding species typically colonises large gaps when they become available (Schnitzler $\&$ Closset 2003). However, as we were unable to determine the historical distribution of gaps in the present study, this explanation cannot be fully validated.

Fig. 2e illustrates that gaps had a regular distribution up to a 20 -m scale. Again this results from the size of the objects with which each of the points in the distribution is associated, in this case the average width of gaps was 3 to $20 \mathrm{~m}$. Gaps were randomly distributed for scales 20 to $72 \mathrm{~m}$ and clustered for scales over $72 \mathrm{~m}$. A conclusion about the pattern of tree mortality (gap creation) could
Fig. 2. Individual tree and gap point distributions tested for deviations from CSR. Solid lines = root square transformation of Ripley's $K$-function $L(d)$; dashed lines = 95\% confidence envelopes.

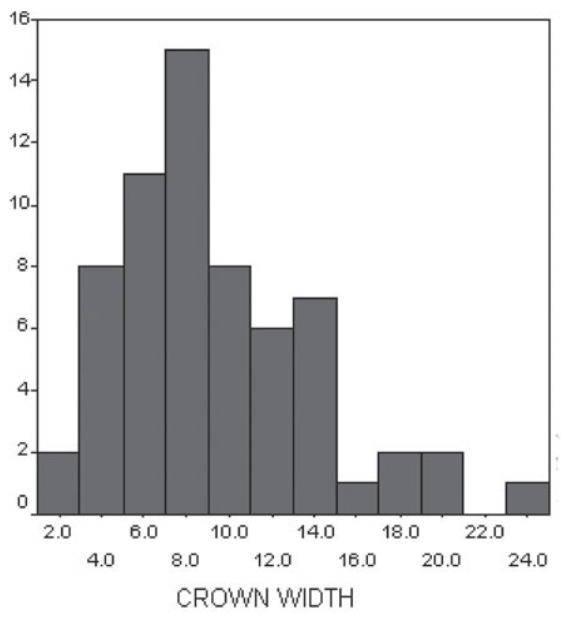

Fig. 3. Histogram of crown width (m) measured in situ for a random sample of Quercus robur trees in Frame Wood ( $n=$ 63 ; mean $=9.3 \mathrm{~m} ; \mathrm{SD}=4.64 \mathrm{~m})$. 

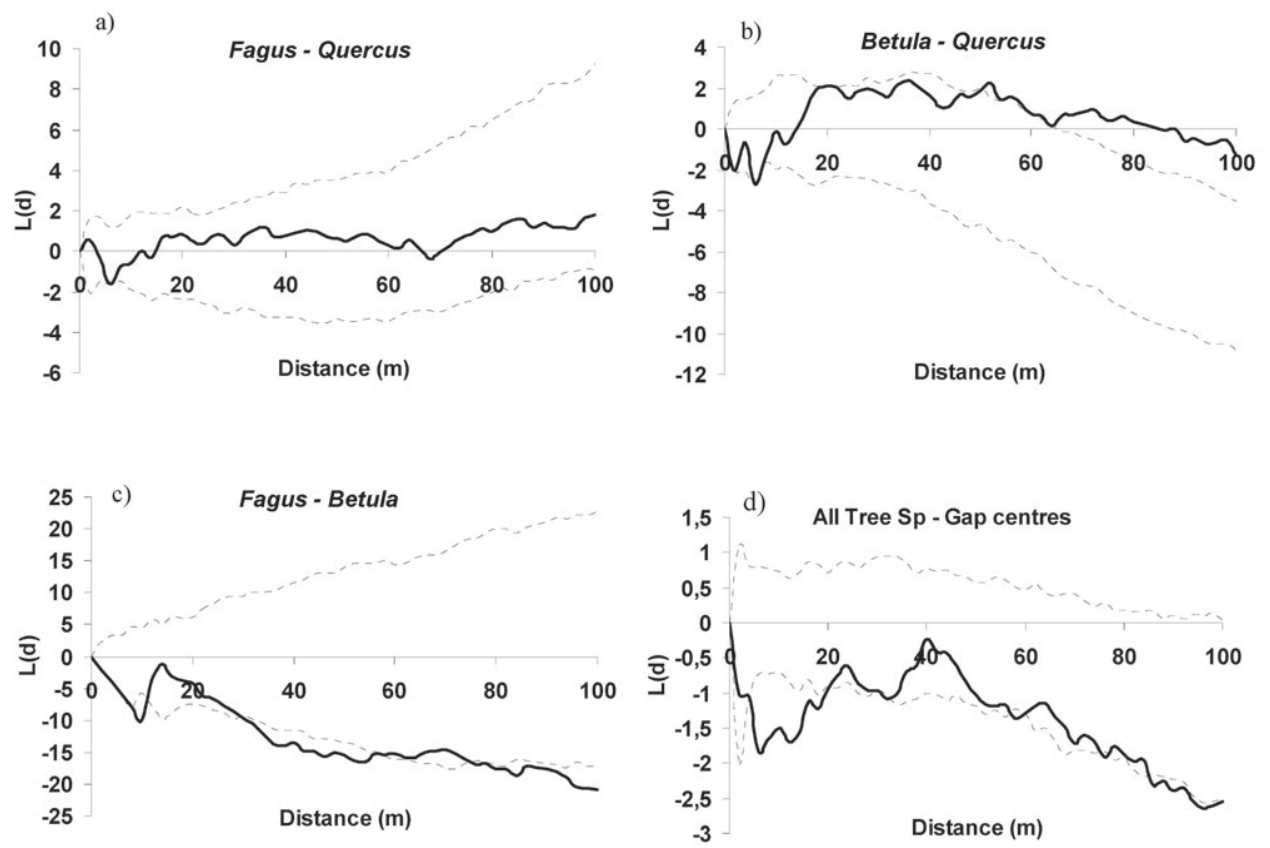

Fig. 4. Associations between the point distributions of different tree species and between trees and gaps. Solid lines $=$ root square transformation of Ripley's $K$-function $L(d)$; dashed lines $=95 \%$ confidence envelopes.

not be derived at this stage as this result refers to all gaps without reference to their area, spatial properties and composition. Subsequent results were more useful in this respect.

The patterns of $Q$. robur and Fagus are spatially independent at all scales (Fig. 4a), B. pendula and $Q$. robur are attractive for scales over $52 \mathrm{~m}$ (Fig. 4b), while Fagus and Betula pendula are generally repulsive (Fig. $4 c)$. These patterns are compatible with the light preferences of the tree species involved, i.e. Fagus and $B$. pendula, have different light preferences and are not likely to have an attractive relation. The pattern of all tree species combined is generally independent from the pattern of gap centres apart from scales up to $20 \mathrm{~m}$ and over $84 \mathrm{~m}$ (Fig. 4d). Repulsion up to $20 \mathrm{~m}$ occurs due to the width of gaps and over 84 due to the segregation of gaps at these scales (compare with Fig. 2e). Each of the individual tree species had spatial patterns that were independent of the gap centre pattern (plots not shown). The independence of the patterns of B.pendula and gaps is interesting, because, as mentioned previously, this light demanding species is known to prefer gap openings. A possible explanation is that most of the $B$. pendula trees were established before the majority of current gaps were created and increasing levels of grazing animals over the last few decades have eliminated chances of regeneration. This sequence of previously effective regeneration followed by a more recent period of little regeneration is further evidenced by the age profile of gaps estimated using log decay, which ranged from 10 to 70 years, with the majority under 30 years old. Such patterns of recent failing regeneration in the face of intensified grazing have also been indicated by a long-term field study in a nearby woodland in the New Forest (Mountford \& Peterken 2003).

\section{Pattern analysis of tree height classes}

Trees in the upper height class (>17.5 m), mostly belonging to $\mathrm{A} 2$ and $\mathrm{B}$ generations, were randomly distributed (Fig. 5a). However, Moeur (1993) indicated that regular patterns of large trees are typical of oldgrowth unmanaged stands. The random pattern in Frame Wood is probably the result of selective (and progressive) felling of early A generation Quercus robur as a management practice during the 18th and 19th century as reported by Flower (1977). Fig. 5 b shows that smaller trees $(<17.5 \mathrm{~m})$ were clustered for all scales greater than those controlled by the crown width dimension. The clustering of younger trees suggests they arose due to the regeneration that colonized gaps when grazing pressure was eased during the period from 1938 until the early 1970s (Tubbs 1986, p. 155).

Fig. $5 \mathrm{c}$ shows that for all species combined, the pattern of trees in the smaller height class $(<17.5 \mathrm{~m})$ had a repulsive relation with the distribution of more mature trees $(>17.5 \mathrm{~m})$. This association appears to be determined largely by the repulsive relation between the 

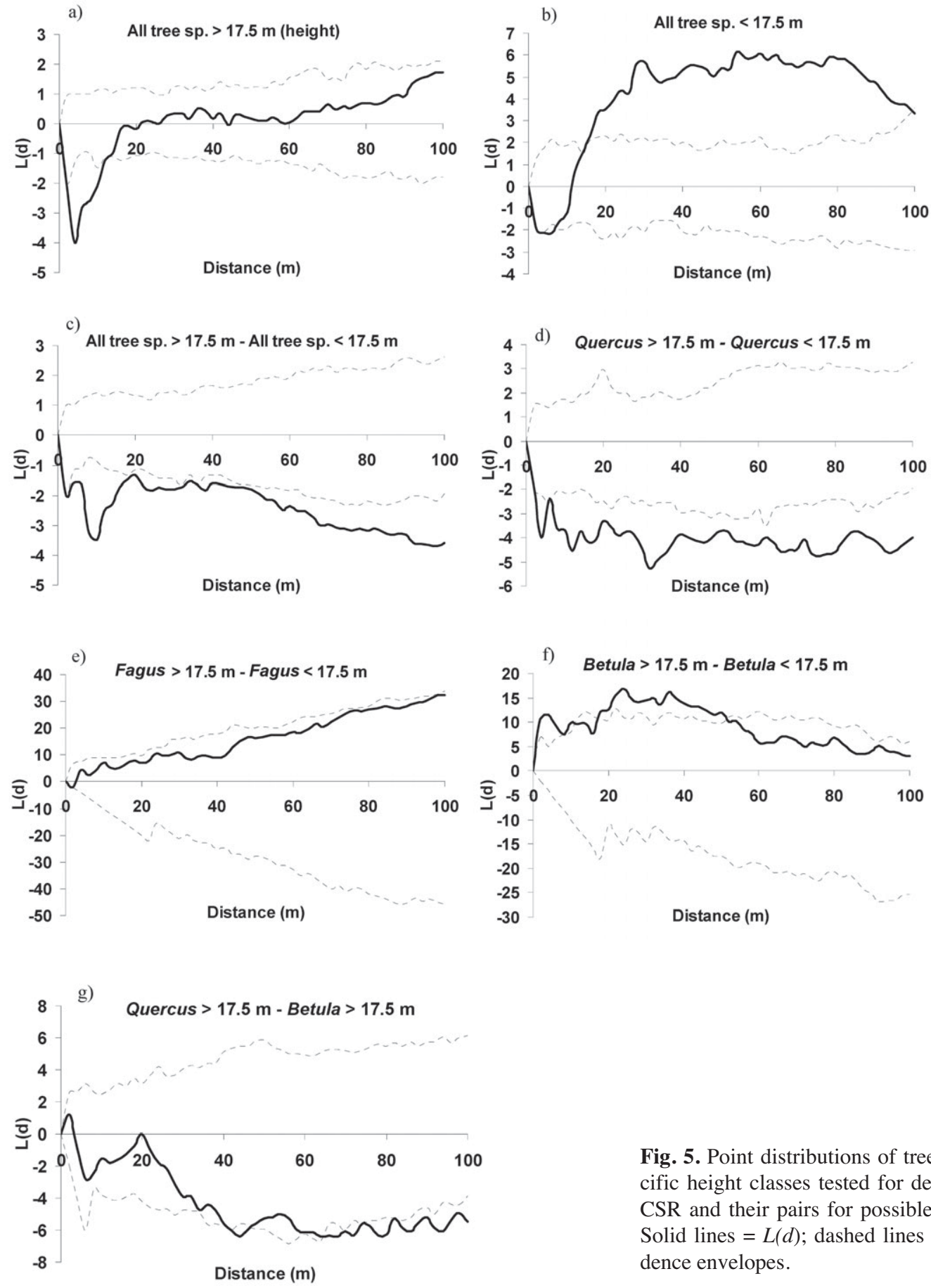

Fig. 5. Point distributions of trees within specific height classes tested for deviations from CSR and their pairs for possible associations. Solid lines $=L(d)$; dashed lines $=95 \%$ confidence envelopes.

patterns of $Q$. robur trees in each of the height classes (Fig. 5d) rather than the distributions of Fagus or B. pendula in the different height classes (Fig. 5e,f). For $Q$. robur, younger trees appear to have established in areas away from the closed canopies of mature trees. Within the upper height class, the patterns of $Q$. robur and $B$. pendula trees had a generally repulsive relation (Fig. $5 \mathrm{~g}$ ), while Fagus and B. pendula were found to be independent at a range of scales and at some scales repulsive. Such contrasting spatial patterns may well reflect the differences between these species in terms of their regeneration strategies and exploitation of ecological niches, that have allowed them to survive to maturity and coexist within the same woodland. 

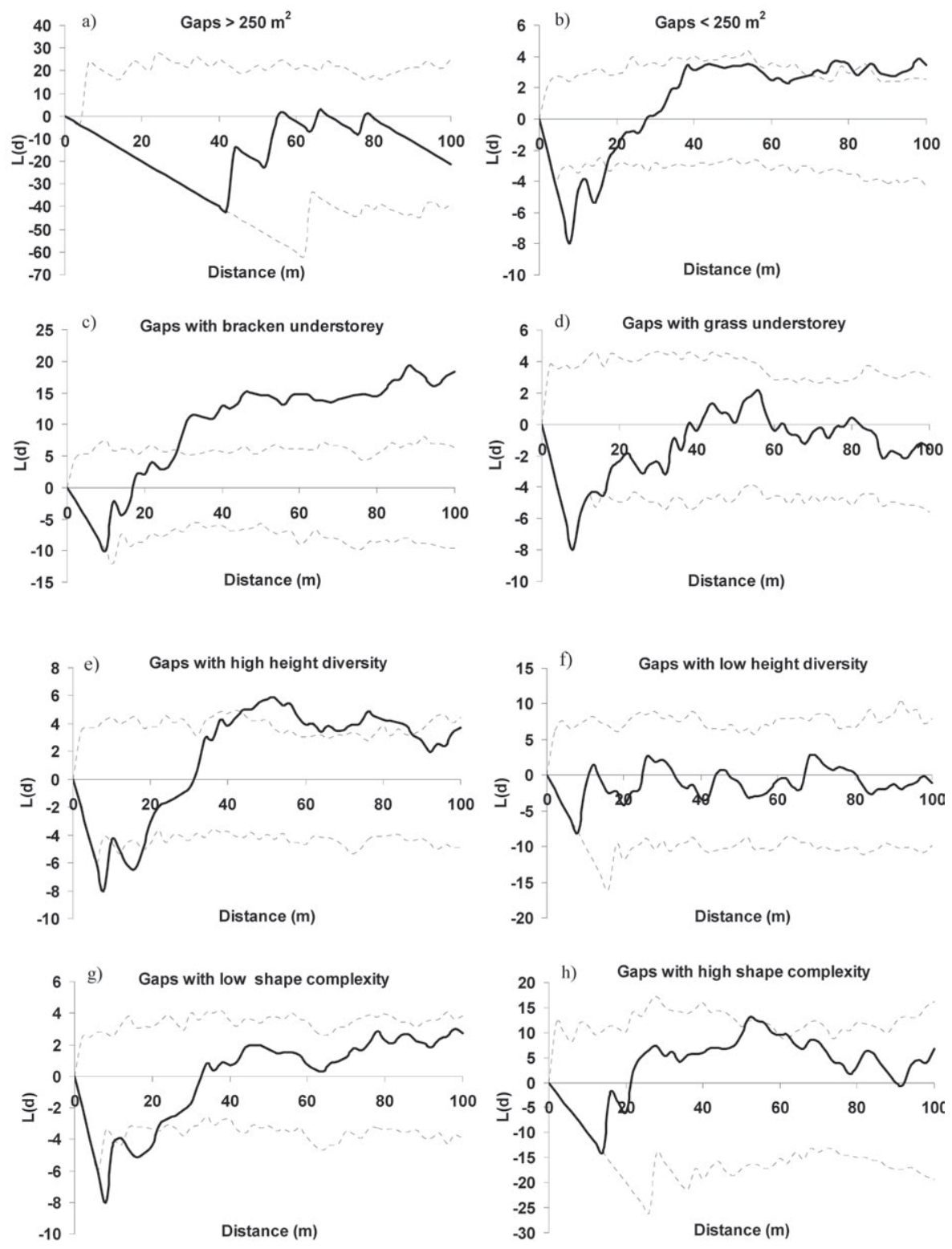

Fig. 6. Point distributions of gap classes tested for deviations from CSR. Solid lines $=L(d)$; dashed lines $=95 \%$ confidence envelopes .

Pattern analysis of gap classes and tree species

Large gaps $\left(>250 \mathrm{~m}^{2}\right)$ were randomly distributed (Fig. 6a). Small gaps $\left(<250 \mathrm{~m}^{2}\right)$ were generally clustered, with significant clustering for scales over $70 \mathrm{~m}$ (Fig. 6b). This clustering together with the high connectivity of gaps in the area (Koukoulas 2001; Koukoulas \& Blackburn 2004) suggests that tree-falls did not occur randomly across the study site. The high proportion of small gaps (83/91) together with their pattern distribution suggests that the few large gaps were created by multiple tree-falls in the neighbourhood. Evidence from the field suggests that this sometimes happens progressively as logs of different age can be found in a single gap. Gaps within which Pteridium was the dominant vegetation type were highly clustered for scales over 30 $\mathrm{m}$ (Fig. 6c). This clustering is understandable as Pteridium is a clonal plant which spreads vegetatively using below-ground rhizomes to create large contiguous patches (Pakeman et al. 1994). In contrast, gaps containing mainly grass were randomly distributed at all scales (Fig. 6d). Gaps containing vegetation with a high height diversity, containing a heterogenous coverage of shrubs, were randomly distributed (Fig. 6e), while those with 
Fig. 7. Associations between the point distributions of trees and gap classes. Solid lines $=$ $L(d)$; dashed lines $=95 \%$ confidence envelopes.

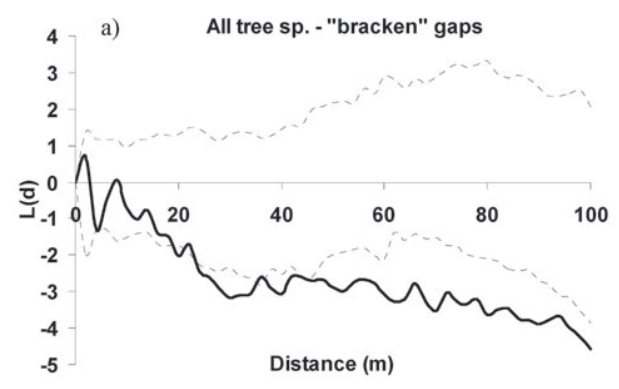

low height diversity were clustered for scales over $30 \mathrm{~m}$ and significantly clustered for scales between $42 \mathrm{~m}$ to 86 m (Fig. 6f). Gaps with both high shape complexity and low shape complexity were randomly distributed over all scales (Fig. 6g, h). The distributions of gaps with different spatial properties have implications for seed establishment and therefore for the formation of future spatial patterns. For example, in a gap with low height diversity, the influence on seed establishment should vary little over the whole gap area, but the shape of the gap and the distribution of surrounding trees will have implications for the distribution of light levels.

The relationships between the patterns of gaps with specific properties and tree patterns were similar for each individual species (except for Fagus trees which are themselves clustered in the NE region of the study area) and all tree species combined. Over most scales the pattern of trees has a repulsive relationship with the pattern of Pteridium dominated gaps (Fig. 7a) but an independent relationship with grass-dominated gaps (Fig. 7b). Repulsion of young trees from Pteridium dominated gaps would be understandable as Pteridium can severely inhibit regeneration (Dolling 1999). However, since most trees in Frame Wood are mature and gaps were created relatively recently ( $<70$ years) the cause of this relation was unclear, but may be an artefact of the random distribution of trees (Fig. 2a) and the clustering of Pteridium dominated gaps (Fig. 6c). Hence, these results suggest that Pteridium has taken the opportunity to invade and dominate clusters of adjacent gaps in the presence of high grazing pressure which has eliminated tree regeneration but against which Pteridium is highly resistant (Mountford \& Peterken 2003).

\section{Conclusions}

The spatial analysis carried out in this research has demonstrated how the patterns of trees and gaps were distributed across a range of scales of the study site. In addition, the associations between patterns of different tree species and between trees and gaps were revealed. Further analysis of the patterns of trees and gaps with specific properties was applied and this helped to understand some of the underlying causes of the initial distributions and associations. Dominant mature trees were randomly distributed, while clustered patterns of younger individuals of particular tree species (Betula pendula and Quercus robur $<17.5 \mathrm{~m}$ tall) were indicative of past regeneration. Small gaps $\left(<250 \mathrm{~m}^{2}\right)$ were clustered at smaller scales, which together with field evidence, indicated that progressive gap enlargement is the likely creation mechanism for large gaps $\left(>250 \mathrm{~m}^{2}\right)$. Several aspects of the spatial patterning and associations between trees and gaps were be related to the management history of the site, in particular variations in the intensity of grazing. By applying spatial analysis to data derived from remotely sensed imagery, detailed spatial information can be derived on a number of key variables of relevance when understanding the stand/community dynamics and ecological interactions within a woodland. Regular monitoring of a site, say on a decadal basis, using these data collection and analytical techniques could make an important contribution to developing a spatially-comprehensive understanding of gap creation mechanisms, the impacts of human and physical disturbance and tree regeneration within woodlands.

Acknowledgements. We are grateful to The UK Natural Environment Research Council for the provision of ATM imagery, the UK Environment Agency for the LiDAR data and Melinda Moeur for use of the RIPK software.

\section{References}

Besag, J. 1977. Contribution to the discussion of Dr Ripley's paper. J. R. Stat. Soc. B. 39: 193-195.

Blackburn, G.A. \& Milton, E.J. 1996. Filling the gaps: Remote Sensing meets woodland ecology. Global Ecol. Biogeogr. 5: 175-191.

Blackburn, G.A. \& Milton, E.J. 1997. An ecological survey of deciduous woodlands using airborne Remote Sensing and Geographical Information Systems (GIS). Int. J. Remote Sens. 18: 1919-1935.

Campbell, G.S. \& Norman, J.M. 1989. The description and measurement of plant canopy structure. In: Russell, B., 
Marshall, B. \& Jarvis, P.G. (eds.) Plant canopies: their growth, form and function, pp. 1-19. Cambridge University Press, Cambridge, UK.

Chen, J. \& Bradshaw, G.A. 1999. Forest structure in space: a case study of an old growth spruce-fir forest in Changbaishan Natural Reserve, PR China. For. Ecol. Manage. 120: 219-233.

Dale, M.R.T. 1999. Spatial pattern analysis in plant ecology. Cambridge University Press, Cambridge, UK.

Diggle, P.J. 1983. Statistical analysis of spatial point patterns. Academic Press, London, UK.

Dolling, A. 1999. The vegetative spread of Pteridium aquilinum in a hemiboreal forest invasion or revegetation? For. Ecol. Manage. 124: 177-184.

Duncan, R.P. \& Stewart, G.H. 1991. The temporal and spatial analysis of tree age distributions. Can. J. For. Res. 21: 1703-1710.

Flower, N. 1977. An historical and ecological study of enclosed and unenclosed woods in the New Forest, Hampshire. Ph.D. Thesis, Department of Geography, King's College, University of London, London,UK.

Goriup, P. (ed.) 1999. The New Forest woodlands: A management history. Forestry Commission, Pisces Publications, Newbury, UK.

Haase, P. 1995. Spatial pattern analysis in ecology based on Ripley's $K$-function: Introduction and methods of edge correction. J. Veg. Sci. 6: 575-582.

Hytteborn, H. \& Packham, J.R. 1987. Decay rate of Picea abies logs and the storm gap theory: a re-examination of Sernander plot III, Fiby urskog, Central Sweden. Arboric. J. 11: 299-311.

Jackson, R.G., Foody, G.M. \& Quine, C.P. 2000. Characterising wind thrown gaps from fire spatial resolution remotely sensed data. For. Ecol. Manage. 135: 253-260.

Koukoulas, S. 2001. Analysing the spatial structure of seminatural deciduous woodlands through high-resolution airborne imagery and Geographic Information Systems. Ph.D. Thesis, Department of Geography, King's College, London, UK.

Koukoulas, S. \& Blackburn, G.A. 2001. Introducing new indices for accuracy evaluation of classified images representing semi-natural woodland environments. Photogramm. Engin. Remote Sens. 67: 499-510.

Koukoulas, S. \& Blackburn, G.A. 2004. Quantifying the spatial properties of forest canopy gaps using LiDAR imagery and GIS. Int. J. Remote Sens. 25: 3049-3071.

Koukoulas, S. \& Blackburn, G.A. 2005. Mapping individual tree location, height and species in broadleaved deciduous forest using airborne LiDAR and multi-spectral remotely sensed data. Int. J. Remote Sens. 26: 431-455.

Liu, Q. \& Hytteborn, H. 1991. Gap structure, disturbance and regeneration in a primeval Picea abies forest. J. Veg. Sci. 2: 391-402.

Moeur, M. 1993. Characterising spatial patterns of trees using stem-mapped data. For. Sci. 39: 756-775.

Moeur, M. 1995. Ripley's K analysis program. U.S. Dept. of Agriculture, Forest Service, Intermountain Research Station, Moscow, Idaho, US.

Morgan, R.K. 1987. Composition, structure and regeneration characteristics of the open woodlands of the New Forest, Hampshire. J. Biogeogr. 14: 423-428.

Mountford, E.P. \& Peterken, G.E. 2003. Long-term change and implications for the management of woodpastures: experience over 40 years from Denny Wood, New Forest. Forestry 76: 19-43.

Pakeman, R.J., Marrs, R.H. \& Jacob, P.J. 1994. A model of bracken (Pteridium aquilinum) growth and the effects of control strategies and changing climate. J.Appl.Ecol.31: 145-154.

Patton, D.R. 1975. A diversity index for quantifying habitat 'edge'. Wildlife Soc. B. 3: 171-173.

Platt, W.J. \& Strong, D.R. (eds.) 1989. Special feature: treefall gaps and forest dynamics. Ecology 70: 535-576.

Ripley, B.D. 1976. The second-order analysis of stationary processes. J. Appl. Probab. 13: 255-266.

Ripley, B.D. 1977. Modelling spatial patterns (with discussion). J. R. Stat. Soc. B. 39: 172-212.

Roberts, S.A., Hall, G.B. \& Calamai, P.H. 2000. Analysing forest fragmentation using spatial autocorrelation, graphs and GIS. Int. J. Geogr. Inf. Sci. 14: 185-204.

Ross, J. 1981. The radiation regime and architecture of plant stands. W. Junk, The Hague, NL.

Runkle, J.R. 1982. Patterns of disturbance in some old-growth mesic forests of eastern North America. Ecology 63: 15331546.

Schnitzler, A. \& Closset, D. 2003. Forest dynamics in unexploited birch (Betula pendula) stands in the Vosges (France): structure, architecture and light patterns. For. Ecol. Manage. 183: 205-220.

Sernander, R. 1936. The primitive forests of Granskär och Fiby: a study of the part played by storm gaps and dwarf trees in the regeneration of the Swedish spruce forest. Acta Phytogeogr. Suec. 8: 1-232.

Shannon, C.E.\& Weaver, W. 1949. The mathematical theory of communication. University of Illinois Press, Urbana, US.

Stoyan, D. \& Penttinen, A. 2000. Recent applications of point process methods in forestry statistics. Stat. Sci. 15: 61-78.

Szwagrzyk, J. \& Czerwczak, M. 1993. Spatial patterns of trees in natural forests of East-Central Europe. J. Veg. Sci. 4: 469-476.

Tubbs, C.R. 1986. The New Forest: A natural history. Collins, London, UK.

Wehr, A. \& Lohr, U. 1999. Airborne laser scanning - an introduction and overview. ISPRS J. Photogramm. 54: 6882.

Wiegand, T. \& Moloney, K.A. 2004. Rings, circles, and nullmodels for point pattern analysis in ecology. Oikos 104: 209-229.

Zenner, E.K. \& Hibbs, D.E. 2000. A new method for modelling the heterogeneity of forest structure. For. Ecol. Manage 129: 75-87.

Received 27 July 2005; Accepted 4 September 2005. Co-ordinating Editor: J. Lepš. 